Historic, Archive Document

Do not assume content reflects current scientific knowledge, policies, or practices. 



\section{BETTER SEED}

Delfos and Stoneville Cottom
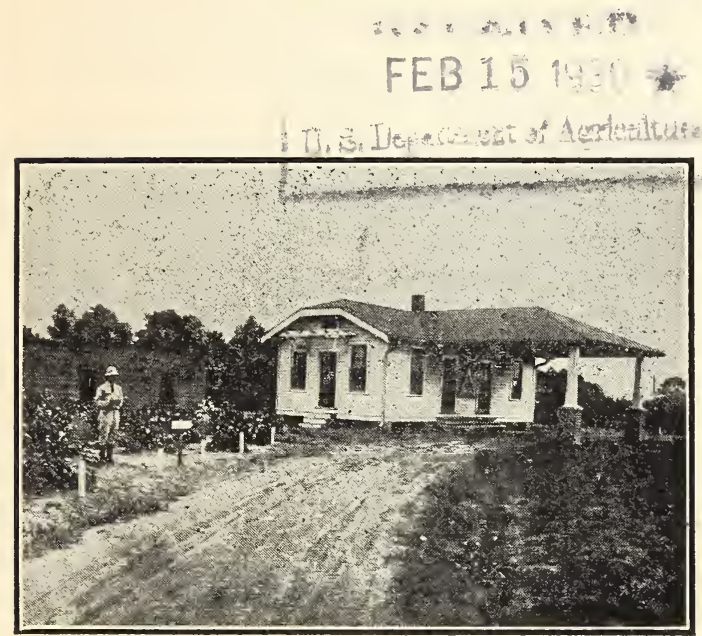

Our office located on breeding and trial grounds

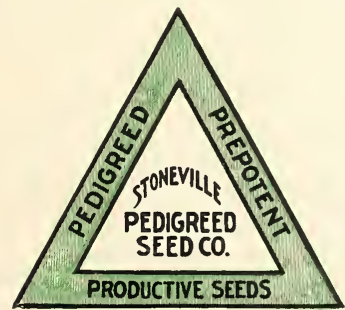

Stoneville Pedigreed Seed Company

Stomeville, Mississippi 
ties. As a result of our efforts, we have developed Stoneville which we consider a Running Mate to Delfos. In our three strains of Stoneville cotton we have cottons that fill every gap in cotton production that Delfos fails to do. These three cottons vary in plant type but all of them are early, prolific, have big bolls, good picking qualities, high lint percentages, storm-proofness, popular staple lengths, wilt resistence and the right type of plant for early and heavy production.

Stoneville Cottons are of Lone Star origin and are not in any way related to Delfos. They were developed from Lone Star-65 which is a strain of cotton thought to be a natural cross hetween Texas Lone Star and Trice. Lone Star-65 was developed at the Delta Branch Experiment Station, Stoneville, Mississippi, in 1915 by Dr. H. B. Brown, who at that time was state plant breeder for Mississippi, and Prof. G. B. Walker, who at that time was director of the Delta Branch Experiment Station, and who is now operating the Stoneville Pedigreed Seed Company. Stoneville strains have made a wonderful record for themselves throughout the entire cotton belt during the past three years and we believe they have an important place in economic cotton production.

\section{STONEVILLE No. 1}

(Lone Star-65-370)

We believe we have in Stoneville No. 1 the nearest approach to the ideal cotton, for the greater part of the cotton belt, that has yet been produced. Note carefully its specifications.

Plants-Very Dwarfy and Stocky.

Maturity-Extremely early (as early as Trice).

Picking Qualities-Good, Large Open Bolls.

Boll Size-Large, 55 to 65 per pound.

Storm-proofness-Good.

Lint Percentage-33 to 36.

Lint Length $-11 / 16$ to $11 / 8$.

Stoneville No. 1 is a new big boll early cotton. In plant type, it is open and spreading and slightly more dwarfy than Delfos. It is very early. In fact, it is just as early as Trice, if not earlier. Bloom counts, over a period of years, indicate that it sets more fruit early than does Trice, but it does not open any earlier. Its extremely large bolls make it an excellent picking cotton. Stoneville No. 1 is the most prolific early big boli cotton we have ever tested. It is really outstanding due to its prolificness, earliness, boll size, and popular staple length. 


\section{STONEVILLE No. 2}

(Lone Star-65-389)

Plants-Medium vigorous and spreading.

Maturity-Early, about the same as Delfos.

Picking Qualities-Good, bolls open well.

Boll Size-Medium large, 60 to 70 per pound.

Storm-proofness-Good.

Lint Percentage-33 to 35 .

Lint Length $-11 / 8$ to $11 / 8 \mathrm{f}$.

Foilage-Medium light.

Stoneville No. 2 is an early, medium large boll, prolific cotton having $11 / 8$ inch staple. It differs from Stoneville No. 1 in that it is a more vigorous grower, has a slightly smaller boll, but better staple. It differs from Delfos in that it has larger bolls and a better lint percentage.

Certainly we could not praise this cotton higher than to say it is a very close relative of Stoneville No. 1. It is probably a better cotton for rich valley land than Stoneville No. 1 in that it has smaller leaves, is more open in plant growth and has some better staple. Its performance this season a real sensation. Investigate it.

\section{STONEVILLE No. 3}

\section{(Lone Star-65-389-58)}

\section{Selected from Stoneville No. 2}

Plants-Rather vigorous and spreading.

Maturity-Medium early, not as early as Delfos-6102.

Picking Qualities_-Good, bolls open well and not sharp pointed.

Bolls- 65 to 75 per pound, nearly round, mostly five locks.

Storm-proofness-Good.

Lint Percentage-35 to 37.

Lint Length-1 1/16.

Prolificness-Very prolific.

Foilar:-Medium light, similar to Stoneville No. $\therefore$.

Stoneville No. 3 is a selection from Stoneville No. 2 and in some ways resembles it. The new strain is more vigorous and slightly later. The lint is somewhat shorter and the bolls are smaller, but the lint percentage is higher. In wilt resistant test the No. 3 ranks higher than No. 2.

Stoineville No. 3 does especially well on the thinner lands where Delfos fails to make enough plant growth. 


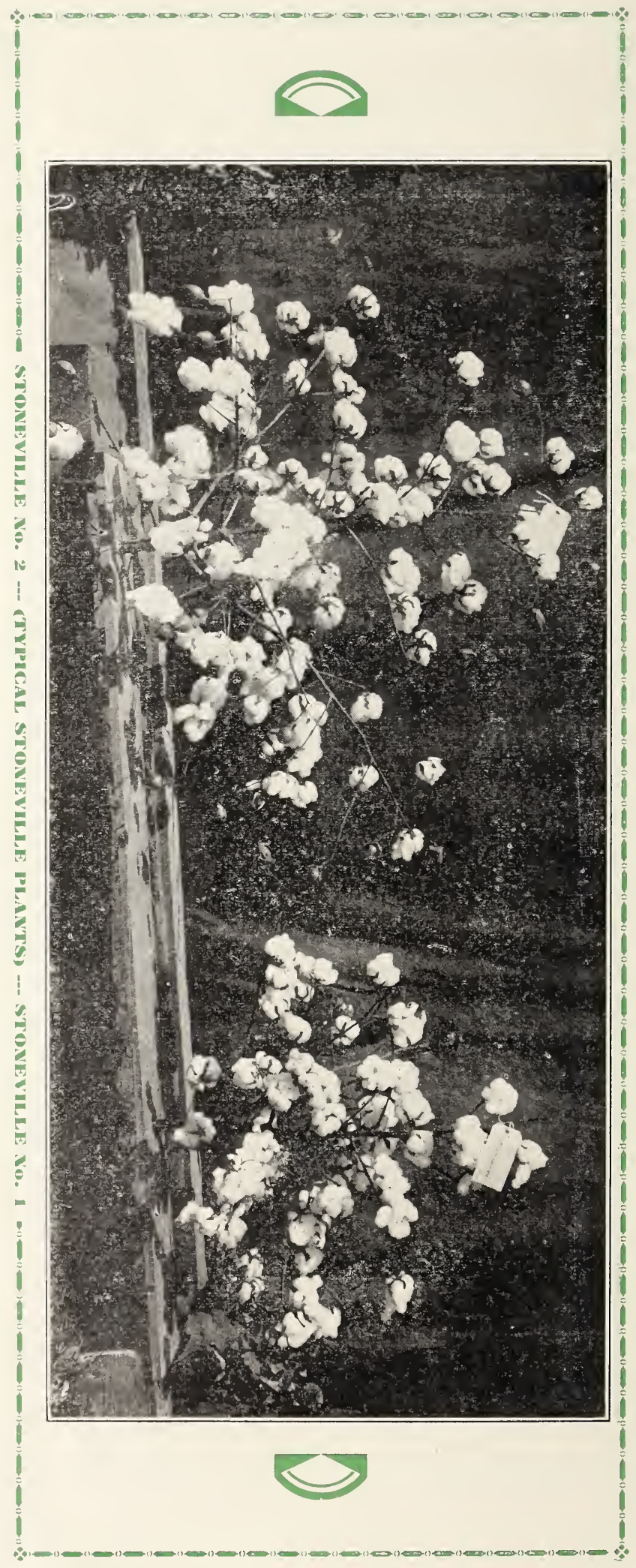





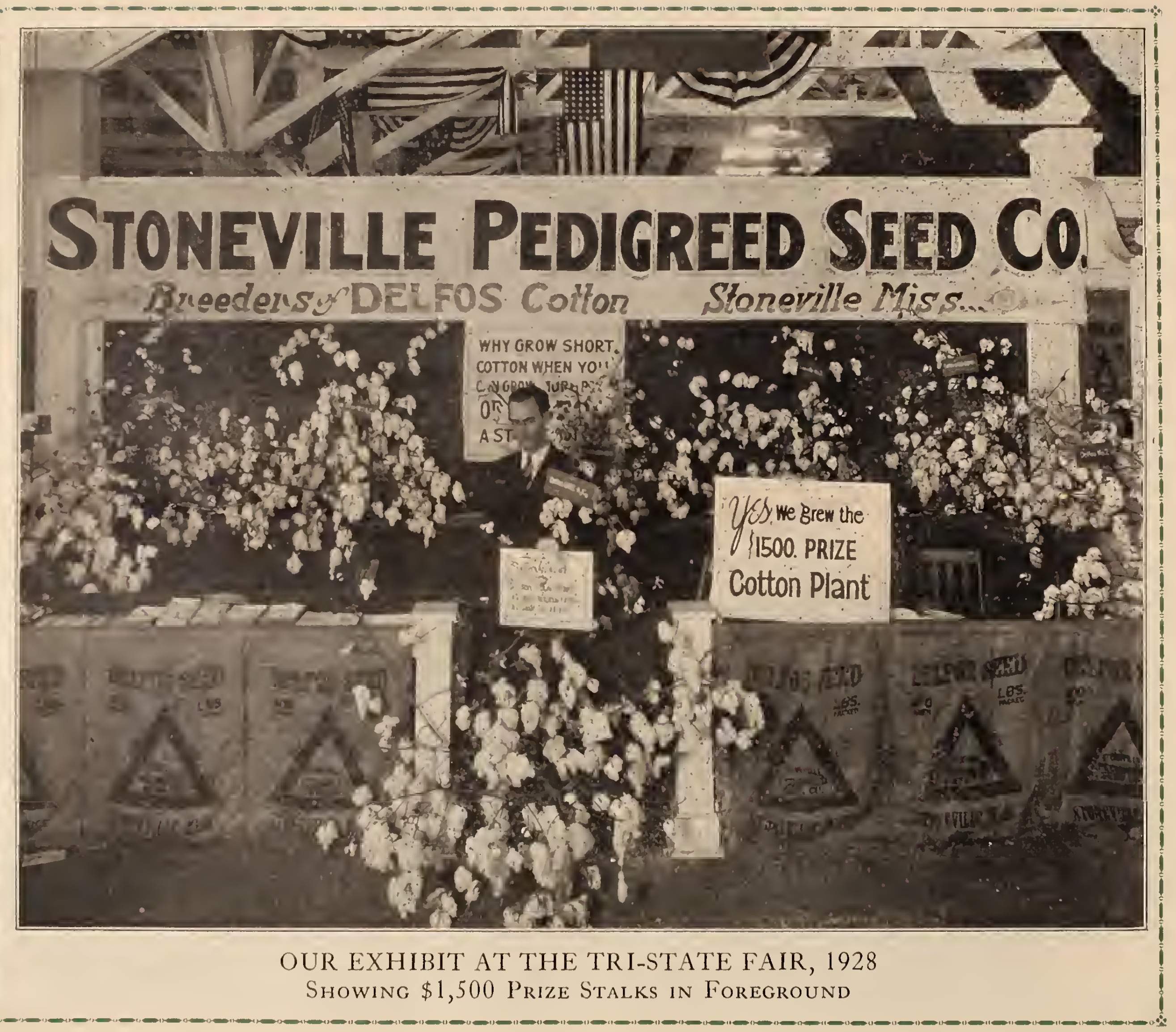




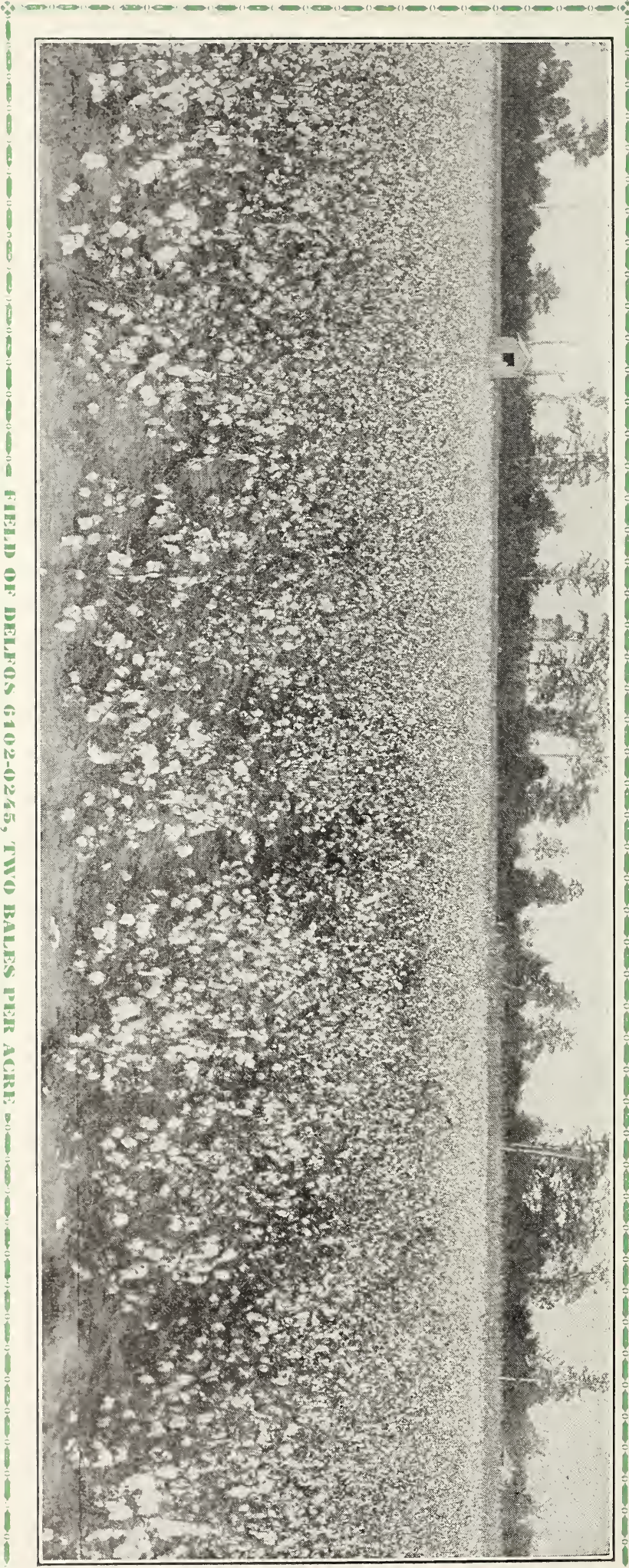

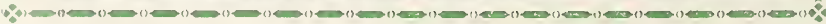




\section{DELFOS-631-463 \\ A Nero Pedigreed Strain of 631}

Plants-Medium vigorous and very spreading.

Maturity-As early as 6102 .

Picking Qualities-Excellent, bolls open well and are fluffy.

Boll Size-60 to 70 per pound.

Storm-proofness-Very good, bolls drooping as to shed water.

Lint Percentage-32 to 33 .

Lint Length-1 $1 / 8$ to $11 / 8 \mathrm{f}$.

Foilage-Extremely light.

Delfos-631-463 is our latest strain developed from 631 but may be a natural cross between 6102 and 631. This cotton has ranked high for four successive years and shows great promise. It appears to combine the plant type, earliness and prolificness of 6102 with the big boll of 631 , and has a better lint percentage than either. Plants are very open and spreading with extremely small leaves which are scarce.

The 463 bolls are on long stems which bend permitting the large bolls to droop and shed water. The bolls open well and are easy to pick.

Delfos-631-463 has more wilt resistence than any of the other Delfos cottons, and still it is a very high yielding cotton.

\section{DELFOS-6102-550. \\ A New Pedigreed Strain of 6102}

Plants-Medium vigorous and very spreading.

Maturity-Very early.

Picking Qualities-Good.

Boll Size -75 to 85 per pound.

Storm-proofness-Fair.

Lint Percentage-32 to 33 .

Lint Length $-11 / 8$ to $11 / 8 \mathrm{f}$.

Foilage-Light.

Delfos-6102-550 is one of our newest strain of 6102. In plant type it is very much like. It is very spreading, early and prolific. It has a better lint percentage and is more prolific than 6102 with about the same staple length.

\section{The Stoneville. Pedigreed Seed} Company can supply the best Delfos Seed at a reasonable price. 


\section{DELFOS-6102-531}

\section{A Nero Pedigreed Strain of 6102}

Plants-Medium, vigorous and spreading.

Maturity-Early, about same as 0245 .

Picking Qualities-Good, better than 6102.

Boll Size-Good for Delfos, 75 to 80 per pound.

Storm-proofness-Fair to good.

Lint Percentage-32 to 33, better than 6102 .

Lint Length-1 3/16, better than 6102 .

Foilage-Light.

Delfos-6102-531 is one of our latest developed strains from 6102. The plants are very much like 6102, but appears to be a little more vigorous. Plants are open and have light foilage. This is a rather uniform strain of cotton, though not as uniform as 0245 . It has larger bolls, better lint percentage and length than 6102 .

\section{DELFOS-6102-0245 \\ A Pedigreed Strain of 6102}

Plants-Open, very low and spreading, many long slender fruiting branches, with very small leaves.

Boll Size -80 to 90 per pound.

Picking Qualities-Good.

Storm-proofness-Fair.

Staple-1 $1 / 8$ to $13 / 16$, good character.

Lint Percentage-31 to 33 .

We believe 6102-0245 to be one of the very best strain of Delfos we have to offer in quantity this season. It is the most prolific blooming Delfos we have ever tested making it a most valuable cotton for boll weevil territories. It has very light foilage and the right type of plant for heavy production. It has made a great record from the Atlantic to Texas. See 1927 report from Scott, Arkansas, experiment station report for the wonderful record 6102-0245 made.

We especially recommend Delfos-6102-0245 for fertile valley lands.

We use every precaution to insure our customers of getting seed that are true to variety and that will sprout and produce a profitable crop. 
DELFOS No. 2

Selected from Delfos 631

Plants-Vigorous, spreading, open plants.

Maturity-Early, though few days later than 6102.

Boll Size -70 to 80 per pound.

Picking Qualities-Good, better than 6102.

Storm-proofness-Much better than 6102 .

Lint Percentage-31 to 33 .

Lint Length-1 $1 / 8$ f to $13 / 16$.

Delfos No. 2 is a late improved strain of 631 , though in many respects resembling 6102 . It combines the prolificness of 6102 with the better picking qualities of 631 , and is more vigorous than either. This strain is especially adapted to the thinner lands on which the other strains of Delfos fail to grow large enough plants. It has considerable wilt resistence, and withstands dry weather exceptionally well. It has a good yield record but is not as uniform as 6102 in plant type.

\section{Play safe and buy your Delfos} Seed from the men who developed this wonderful cotton.

\section{DELFOS-6102-911 \\ A Selection from 6102}

Plants-Very open. Little taller and more vigorous than 6102 .

Maturity--Very early.

Boll Size -75 to 85 .

Picking Qualities-Good.

Storm-proofness-Little better than 6102 .

Lint Percentage-31 to 33 .

Staple $-11 / 8$ to $13 / 16 \mathrm{f}$.

Delfos-6102-911' differs from 6102 in that it is a more vigorous growing plant, a shade better staple and a larger boll. It is also more uniform. This cotton has a good record in net returns. It was one of the highest yielders in our test the past two seasons.

\section{"HONEST SEED}

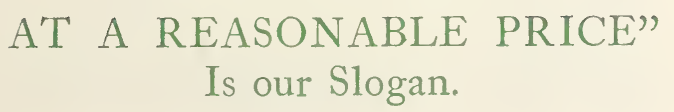




\section{DELFOS-6102-A2-C3 \\ Selected from Delfos-6102}

Plants-Larger and more uniform than 6102 and more disease resistant.

Maturity-Very early.

Boll Size-80 to 90 per pound.

Picking Qualities-Good.

Storm-proofness-Fair.

Lint Percentage-31 to 33.

Staple $-11 / 8$ to $13 / 16$.

Delfos-A2-C3 has all the good qualities of the original 6102 strain with many added virtues. It is probably the best all round "Rough and Tumble" Delfos octton to be had today. We are proud of the record this cotton has made. If you are looking for a good original 6102 cotton at a low price this should be your choice. It never fails to please.

\section{ONLY THE BEST IS WORTH THE PRICE YOU PAY!}

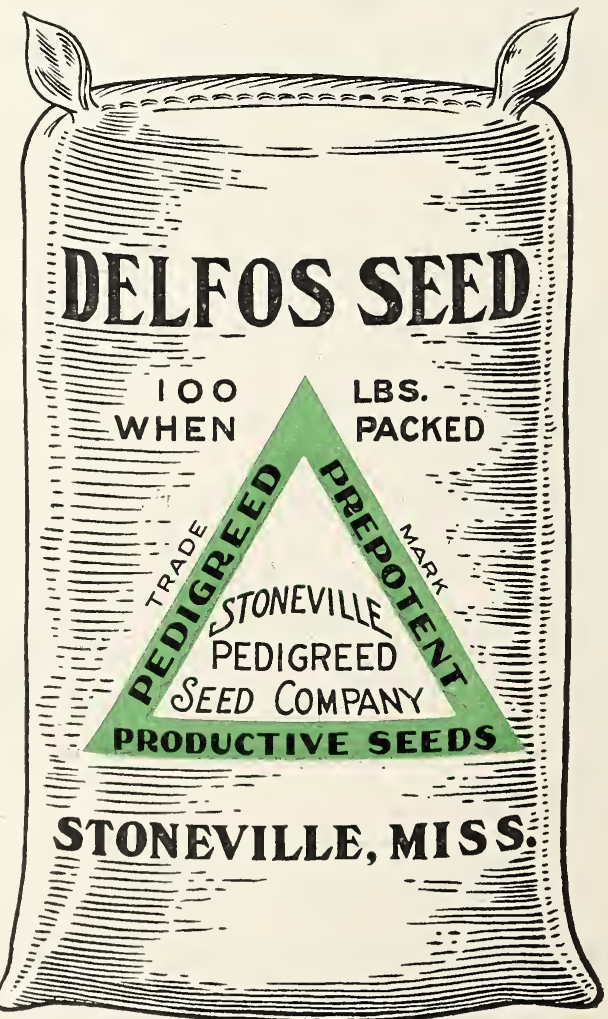




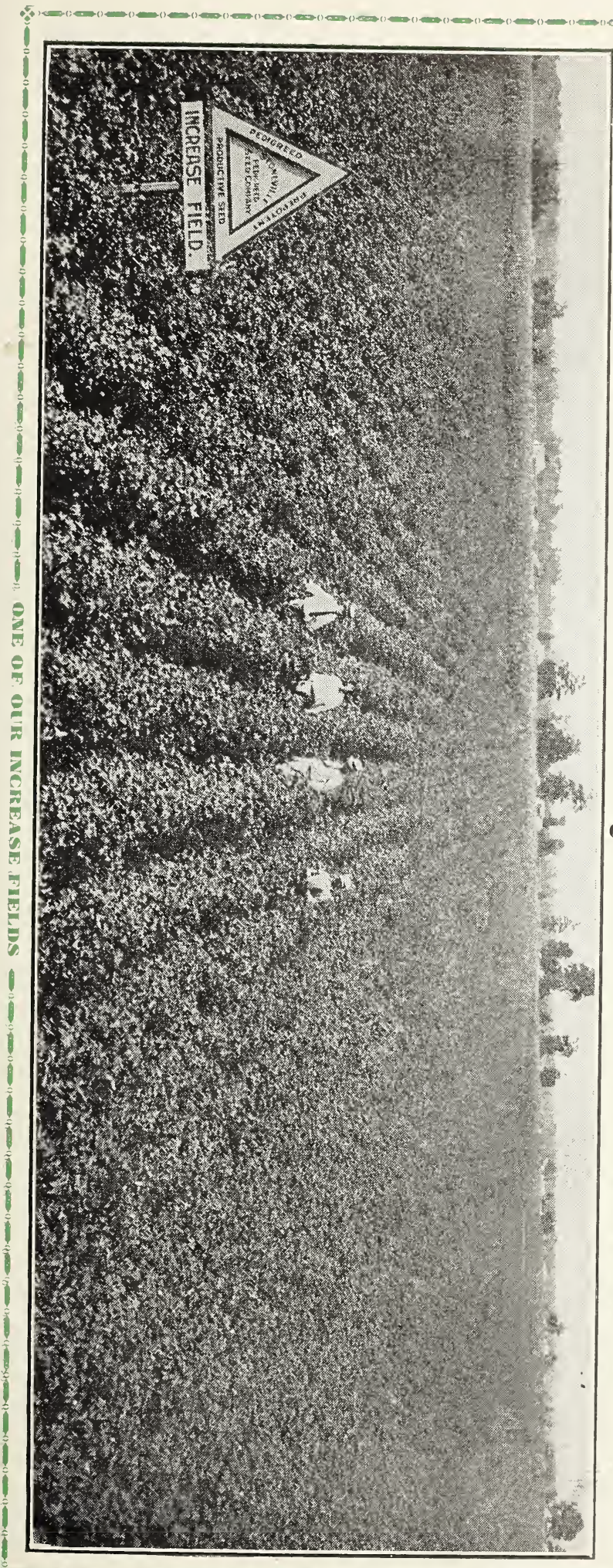


-

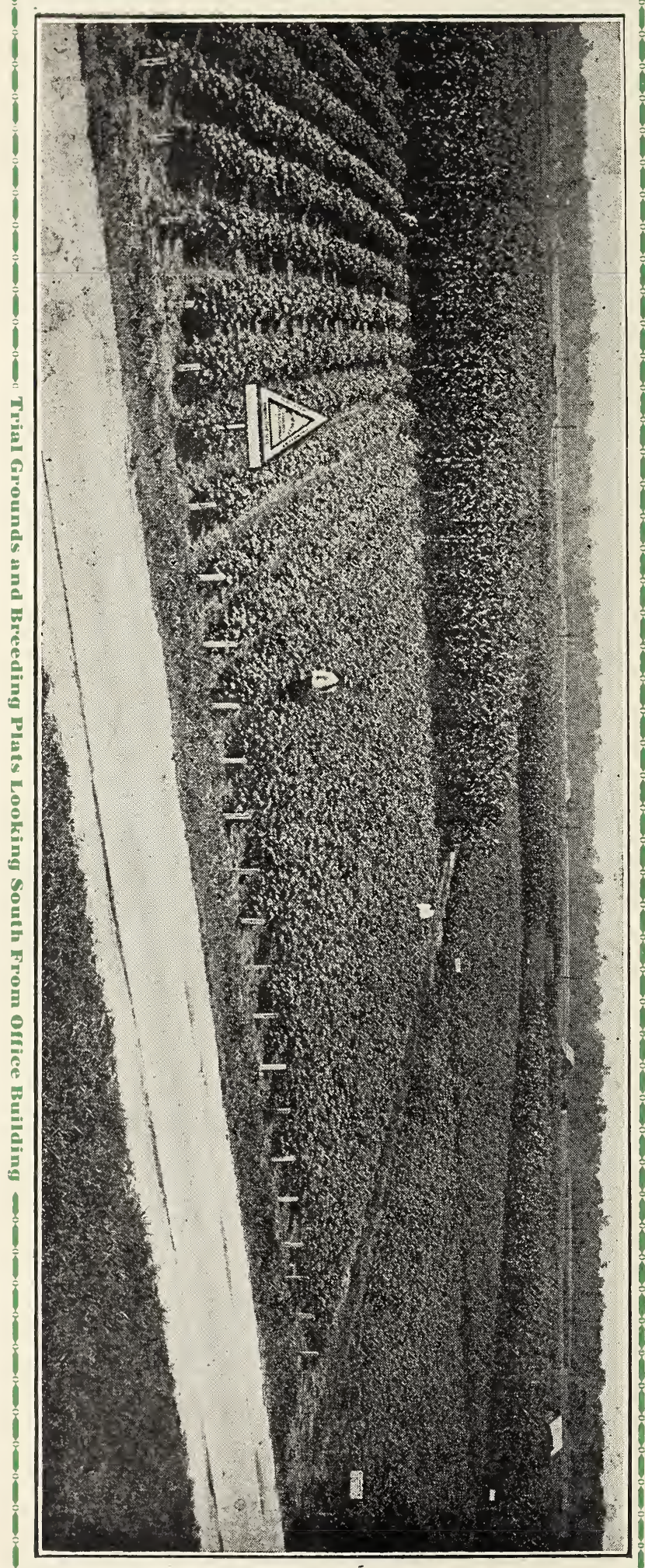

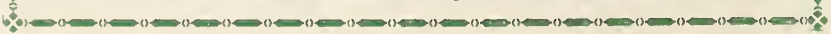

